\title{
Introducing cooperative learning: students' attitudes towards learning and the implications for self-directed learning
}

\section{Elsa Mentz and Sukie van zyl}

\begin{abstract}
This article reports on research that aims to enhance self-directed learning by introducing cooperative learning strategies. The two-fold aim of this research was firstly to determine whether the implementation of cooperative learning in a Computer Application Technology class of first-year students contributed to positive attitudes towards learning, and secondly, whether students' attitudes towards learning, after completion of the cooperative learning intervention, related to their self-directedness. We conclude that the implementation of cooperative learning in a Computer Application Technology first-year class positively contributes to students' attitudes towards learning and their attitudes towards learning related to their perceived self-directed learning (SDL) readiness.
\end{abstract}

\section{Introduction}

Widespread concerns exist about the preparation for lifelong, self-directed learning (SDL) of teachers in teacher preparation programmes. Teacher training programmes should equip teachers so that they can support learners to be lifelong, self-directed learners. In an ever-changing world, teachers continually need to improve their professional development and must be able to create meaningful learning environments not only for themselves, but also for their pupils (Ahonen, Pyhältö, Pietarinen and Soini, 2015, p.97). As interpreters of the curriculum, teachers are in a particularly good position to lead students to deal with the rapidly changing environment. They therefore need to stay abreast of new inventions, skills and knowledge and be selfdirected in their own learning, not merely waiting for formal professional development initiatives.

Quite often traditional instructional approaches still focus on mere memorization, and representation of facts and knowledge are still the norm in teacher preparation programmes and at school level. Students tend to focus on how well they can memorize and represent facts and knowledge rather than on 
SDL skills that can equip them for lifelong learning and that can provide the key to survival and success to cope with the challenges of the $21^{\text {st }}$ century.

It is estimated that 65 percent of children in the United States will end up in jobs that have not been invented yet (Davidson, 2012). Although we do not know what those jobs will be, they surely will require skills that extend beyond the mere memorization of knowledge obtained from the transmission of knowledge in a lecturer-centred environment. Instead, lecturers as facilitators and teachers should strive to implement active learning strategies into a student-centred learning environment and continuously seek for ways in which students can be prepared for their eventual place in the world of work. Facilitators in teacher training institutions have to encourage student teachers to take responsibility for their own learning as self-directed lifelong learners in order to apply those skills in their own classes when preparing learners for the new challenges that await them.

This article reports on the second phase of a design research study (cf. Collins, Joseph and Bielaczyc, 2004; Kelly, Baek, Lesh and Bannan-Ritland, 2008) that aims at enhancing SDL by introducing cooperative learning strategies. During the first phase, it was clear that a cooperative learning intervention contributed significantly to students with moderate SDL skills in that their perceived self-directedness increased after the cooperative learning intervention. Students who already showed high SDL skills did not benefit significantly from the cooperative learning intervention, as their selfdirectedness decreased slightly after the cooperative learning intervention. From the cooperative learning perception questionnaire used in the first phase of the research, it was clear that not all students perceived the cooperative learning intervention equally positively. Two questions emerged from the first phase of the study, namely: did the students' attitude towards learning change as a result of the cooperative learning intervention and, did their attitudes towards learning relate to their self-directedness? The second phase of this study examined students' attitudes towards learning before and after the cooperative learning intervention took place as well as how their attitudes related to their self-directedness. The two-fold aim of the second phase of the research was firstly to determine whether the implementation of cooperative learning into a computer applications technology (CAT) first-year class contributed to positive attitudes towards learning, and secondly, whether students' attitudes towards learning, after completion of the cooperative learning intervention, related to their self-directedness. 


\section{Theoretical and conceptual framework}

The research was undertaken from a pragmatic-constructivist theoretical perspective. As constructivists, we relied on the fact that reality is constructed within a social context (Mertens, 2005), but in accordance with the pragmatic paradigm, we placed the research problem at the centre of the investigation and all methods were selected to understand and gain insight into the problem (Creswell, 2009). We relied on the students' views of the social context being studied, as SDL and assumed perceptions of cooperative learning could best be measured through the perceived experiences of the students. As this research was oriented towards real-world practice to understand human experiences better, the pragmatic-constructivist research paradigm provided for the necessary means to focus on the problem at hand (Mackenzie and Knipe, 2006). We aimed to understand human experiences in a class where active learning strategies and social interaction were applied.

\section{Self-directed learning}

Self-directed learning can be described as a process in which students gradually accept more responsibility for their own learning by -

- $\quad$ taking initiative, with or without the assistance of others, in identifying their own learning needs;

- formulating their own learning goals and outcomes;

- identifying own resources for learning;

- choosing and implementing learning strategies suitable for their own learning; and

- $\quad$ assessing their achievements of set learning outcomes (Knowles, 1975).

The value of self-directed learning lies in the ability to engage continually in learning and construction of new knowledge after graduation (Raidal and Volet, 2009). Guglielmino (1978) describes a highly self-directed learner inter alia as one who has a strong desire to learn, who is able to use basic study skills, who has a high sense of curiosity and who enjoys learning. This is exactly the type of teacher that is needed to equip the learners in this century in South African schools. 
Warburton and Volet (2012, p.10) describe self-directed learners as "students who ask appropriate questions to guide their enquiry, interrogate the assumptions behind the ideas presented to them, identify appropriate resources and tools and use or modify these strategically to achieve their learning goals". Self-directed learners approach learning "more purposefully and with greater motivation" (Knowles, 1975, p.14). Long and Associates (2000) went further and identified motivation as one of the driving forces of a self-directed learner.

Francom (2010) lists four general principles to foster student self-direction. Firstly, student readiness should be taken into account when deciding on the amount of self-direction required. Readiness is described by Grow (1991) as a combination between ability and motivation and can be situational and task specific. Students' previous knowledge and experiences of SDL are, according to Francom (2010), predictors of their SDL effectiveness in a given situation and can thus contribute to their readiness. Following the first principle, the second principle, namely a gradual progression from teacherdirected instruction to SDL, is a given. Students with a tendency to depend strongly on the guidance of the teacher should not be left to their own devices, but should still receive some form of support, but that should gradually be reduced. Thirdly, the acquisition of subject matter knowledge and SDL should not be separated. Guglielmino (2013) provided guidelines to integrate SDL into the curriculum. These guidelines include building a class climate supportive of SDL, promoting individual awareness of SDL and encouraging reflection, metacognition and assessment strategies that build SDL skills and abilities. Lastly, students should be provided with authentic tasks to practise SDL. Authentic tasks have real world relevance and tend to increase students' motivation for learning (Parsons and Ward, 2011). These four principles emphasize the important role that the facilitator has in this process of supporting students to become more self-directed. The intentional move from teacher-directed instruction to SDL should be carefully planned. Francom (2010) states that the nature of a teacher-directed learning environment is characterized by learning activities chosen by the teacher and learning resources given to students, which limit students' opportunities to take responsibility for and ownership of their learning. It is therefore evident that teacher-directed classroom activities can undermine self-direction in learning. Important steps to develop SDL include the shift in responsibility for learning from the facilitator to the student while the facilitator still facilitates students' activities and encourages cooperation, inquiry and critical questioning and 
provides opportunities for students to reflect on own thinking and learning (Francom, 2010).

A large volume of research (Blumberg, 2000; Lohman and Finkelstein, 2000; Malan, Ndlovu and Engelbrecht, 2014) confirms that active learning strategies such as problem-based learning and other collaborative teaching and learning environments that are student-directed, can foster SDL. Warburton and Volet (2012) planned a group content quiz assignment where students were required to work collaboratively, ask questions and seek, recognise, use and evaluate appropriate resources in order to achieve the learning goal. They found that this group assignment successfully helped students to develop some basic skills for SDL. Although cooperative learning is in many ways similar to problem-based learning, not much research has been done on cooperative learning to actually foster SDL.

\section{Cooperative learning}

Cooperative learning occurs when small groups work together to accomplish a common goal while maximizing learning of everyone in the group (Johnson and Johnson, 2013). It is an active and independent form of learning that motivates students to obtain more information, discover new learning strategies and construct their own knowledge (Hmelo-Silver, 2004; Tan, Lee and Sharan, 2007).

According to Johnson and Johnson (2013), five basic elements - positive interdependence, individual accountability, interpersonal and small group skills, face-to-face promotive interaction, and group processing - should form part of any cooperative learning environment. Facilitators can foster positive interdependence by structuring cooperative tasks with a clear goal and in such a way that all members of the group are actively involved. Students have to realize that each group member has an individual contribution to make and the group cannot succeed unless every group member succeeds. The main aim of a cooperative environment is for students to learn together and to then perform alone (Johnson and Johnson, 2013). Everyone should be responsible not only for their own learning, but also for the learning of all members of the group. The facilitator can foster individual accountability through individual and group assessment, allocation of roles within the group and through observing members' contributions within the group (Johnson and Johnson, 
1999, 2013). To foster face-to-face promotive interaction they concluded that group members should provide each other with efficient assistance in order to encourage each other to achieve the learning goals. The assistance can be done through exchanging resources and knowledge, and challenging each other's conclusions and reasoning (Johnson and Johnson, 1999, 2013). Cooperative learning also necessitates good interpersonal and small group skills as an important element of successful cooperation. Students have to communicate accurately, listen carefully to one another and resolve conflict, if necessary (Johnson and Johnson, 1999). The success of cooperative learning also depends on the group's ability to reflect on their cooperation in order to achieve the goals. To foster group processing, there should be an opportunity for students to reflect on the group's actions and to provide feedback to one another in terms of how well they have functioned and how valuable their contributions were in achieving the goals of the group. According to Johnson and Johnson (2013), the facilitator should emphasize positive feedback and also provide feedback to each group on how well they are working together.

The five elements of cooperative learning closely relate to the steps to develop SDL. As self-directed learners often need others to discuss and clarify problems and share resources (Knowles, 1975), cooperative learning provides a platform to practice face-to-face promotive interaction as well as interpersonal and small group skills while simultaneously obtaining subject matter knowledge (Felder and Brent, 2007, p.11).

Several advantages of cooperative learning have been reported. In 1991, Slavin reported that cooperative learning could foster students' independence in learning (Slavin, 1991). Shimazoe and Aldrich (2010) contend that cooperative learning promotes deep learning, improves academic achievement, social skills and higher-order critical thinking skills, and develops positive attitudes toward autonomous learning. Felder and Brent (2007) argue that cooperative learning works well because students have the opportunity to be actively involved in the learning instead of sitting and listening passively. Weak students who tend to quit when working on their own now have the support to continue, which contributes to improvement in academic achievement (Felder and Brent, 2007). High academic achievers often need to explain or clarify learning content when they realize that others are counting on them. This results in more motivated learners (Felder and Brent, 2007). All of these advantages are characteristics of a self-directed learner and are closely linked to Idros, Mohamed, Esa, Samsudin and Daud's 
(2010) crucial aspects for SDL, namely collaboration, cooperation and consensus making.

If the five elements of cooperative learning are not implemented correctly, these advantages will not be obtained and students' attitudes towards cooperative learning will turn out to be negative (Mentz, Van der Walt and Goosen, 2008).

\section{Attitudes towards learning}

Aiken (1996) defines attitude as a condition where an individual responds positively or negatively to something or someone. Brown (1980) considers attitude as a set of personal feelings and opinions, while Gardner (1985) defines attitude as one's instincts, notions or feelings about any specified topic. According to Farzaneh and Nejadansari (2014), attitudes can influence the way students think, understand, feel, and eventually how they behave. Thus, attitudes have cognitive, affective and behavioural components. Beliefs, ideas and opinions about the object of the attitude form part of the cognitive component. Feelings and emotions that one has towards an object form part of the affective component, and one's actions and intentions towards the object form part of the behavioural component (Wenden, 1991). Attitude is a mental state, which can drive a person's actions (Richardson, 1996).

Within a teaching and learning environment, the unsuccessful performance of a task will most probably result in a negative attitude towards the task. Attitudes towards learning and motivation are closely linked, therefore negative attitudes have an influence on student motivation, which will subsequently influence success (Acikgoz Un, 2007; Sen, 2013). The evaluation of students' attitudes can provide valuable insight into the application of suitable teaching-learning strategies and ways in which students should be supported. A number of previous studies (Farooq and Shah, 2008; Ma and Kishor, 1997; Yenilmez, 2007) indicate a positive relationship between individual achievements of students and their attitudes towards the specific field of study. 
Bringing it all together

From the above discussion about SDL, cooperative learning and attitudes towards learning, a number of relationships between these concepts have been drawn. The affective, cognitive and behavioural attitudes can be linked to some different characteristics of a self-directed learner on the one hand, and to the five elements of cooperative learning on the other hand (see Table 1). Certain SDL characteristics were linked to affective, cognitive and behavioural attitudes respectively. Furthermore, the five elements of cooperative learning were also linked to attitudes and characteristics of SDL. 


\section{Table 1: Relationship between cooperative learning, attitudes towards} learning and SDL

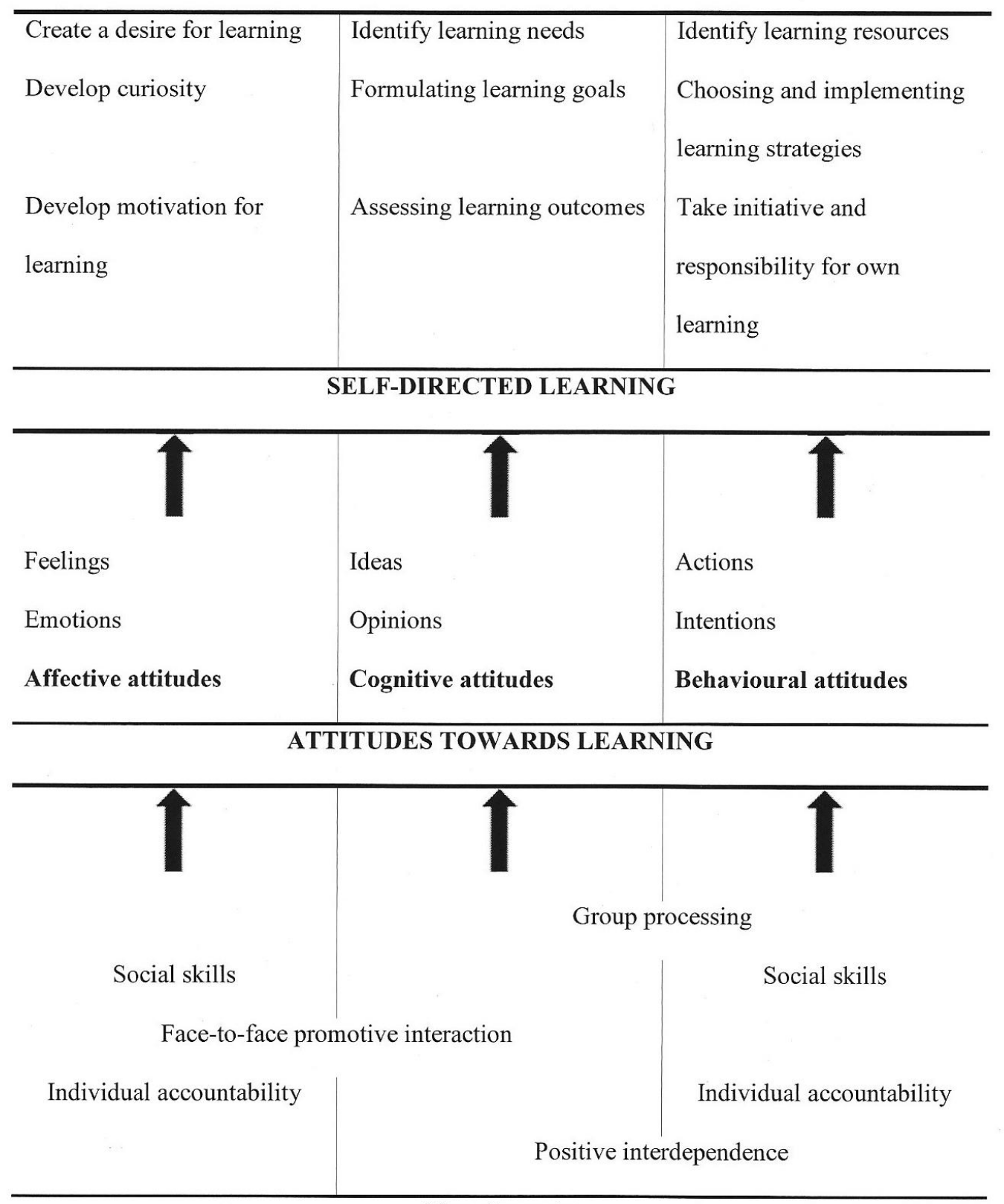

Five elements 


\section{Empirical investigation}

We used an explanatory QUAN-qual mixed method design (Creswell, 2008). The population consisted of 57 CAT first-year student teachers within the Faculty of Education Sciences at the North-West University (Potchefstroom Campus) in South Africa. A total of 41 female and 16 male students between the ages of 18 and 21 voluntarily participated in the research. Unfortunately, only 24 students completed the pre-tests and post-tests of both measuring instruments. Ethical clearance was obtained from the university and all participants gave informed consent.

A 22-item cooperative learning perception questionnaire with six items specifically measuring students' attitudes towards cooperative learning was applied before and after the six months intervention. The cooperative learning perception questionnaire items took the form of a 5-point Likert-type scale with 1 being 'strongly disagree' and 5 being 'strongly agree'.

Self-directedness in learning was measured with Williamson's (2007) Self-Rating Scale of Self-Directed Learning (SRSSDL). The SRSSDL consists of 60 items, which can be grouped into five factors, namely awareness (questions relating to students' understanding of aspects contributing to becoming self-directed), learning strategies (questions on strategies necessary to become self-directed), learning activities (questions on learning activities students should engage in to become more self-directed), evaluation (questions on specific attributes to monitor learning activities) and interpersonal skills (questions on interpersonal relationships which are important for SDL). A five-point Likert-type scale is used to rate each item, with $5=$ always and $1=$ never. All items are positively stated: a maximum score of 300 and a minimum of 60 can be obtained (Williamson, 2007). Williamson defines a score of between 60 and 140 as 'low' and indicating a definite need for facilitator intervention and guidance. An SDL score that falls between 141 and 220 is considered moderate and implies that there are still areas of improvement needed in SDL. A high score is between 221 and 300, indicating effective SDL. Williamson (2007) reports a Cronbach's alpha coefficient on all five areas of the SRSSDL above 0.7 and reached the conclusion that the SRSSDL is a valid and reliable instrument in assessing self-directedness in learning. 
We conducted interviews with students after the intervention, to determine their attitude towards learning. The participants were selected through stratified random sampling. We divided students into three categories according to their achievement in the module and randomly selected 5 participants from each category. These students were invited to individual interviews and eventually 14 students participated in the interviews. During the interviews students had to explain how they experienced the cooperative learning strategies which we implemented in this class. They had to elaborate on the influence of the cooperative learning strategy on their achievement of the learning outcomes, their learning gain, the way in which they prepare for these classes, as well as the influence of this strategy on their interest in the subject.

Reliability of both the SRSSDL (0.83) and the 6-item attitude questionnaire (0.81) with high Cronbach alpha coefficient values was obtained.

Keeping in mind the small group size, we used a dependent t-test with Cohen's d-values as well as the Wilcoxon Ranks test with non-parametric effect sizes (Field, 2005) to determine the differences between the pre-tests and post-tests for students' attitudes towards learning as well as students' self-directedness.

During the second phase of this design research study, we revised and refined the cooperative learning intervention used in the first phase of the study, while paying specific attention to the proper incorporation of the five elements of cooperative learning into each cooperative learning session. The refinement was based on our experiences and observations as well as student feedback from the first phase. In contrast to the previous year, individual accountability was fostered by individual tests after each cooperative learning session in an effort to eliminate any free riding in the group.

Qualitative interviews were transcribed and then analysed by means of Atlas.ti. We used selective coding to code any data from the interviews that related to the students' positive or negative attitudes toward learning. We used the affective, cognitive and behavioural components of attitudes (see 1.2.3) as pre-determined categories in this regard. In each category different themes emerged from the data. Two researchers coded the data independently. Differences between their interpretations were discussed and solved. 


\section{Results}

Quantitative research

Table 2 presents the mean scores of the total group of students in the different categories of the SRSSDL for pre-tests and post-tests. The total group improved on all categories of the SRSSDL except for Evaluation, where there was a slight decrease, and Awareness which remained the same. Nevertheless, the improvement was not statistically or practically significant. We then divided the total group into two separate groups - those with a moderate SDL score in the pre-test and those with a high SDL score in the pre-test (No students obtained a low SDL score). Students with a moderate SDL score at the beginning of the cooperative intervention improved significantly on all categories and this improvement is of practical significance (See Table 2). Although a decrease was noted in all categories of those students with a high SDL score, all the scores were still in the high category. The decrease was also only of practical significance in some cases. The decrease in high SDL scores could be attributed to the fact that these students are used to working alone and now have to work together and take responsibility of all group members' learning and explain their knowledge to the group. 


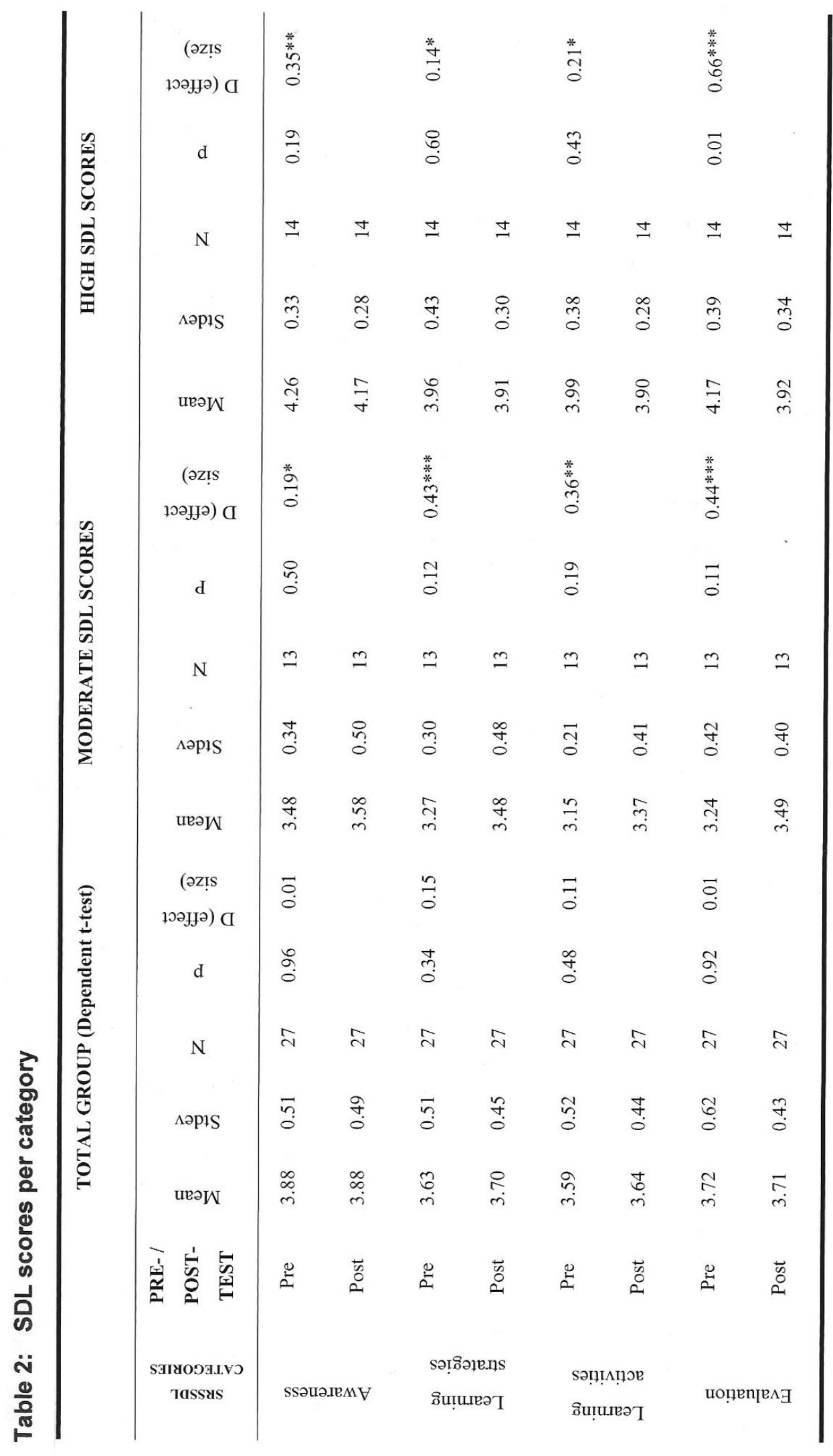


92 Journal of Education, No. 64, 2016

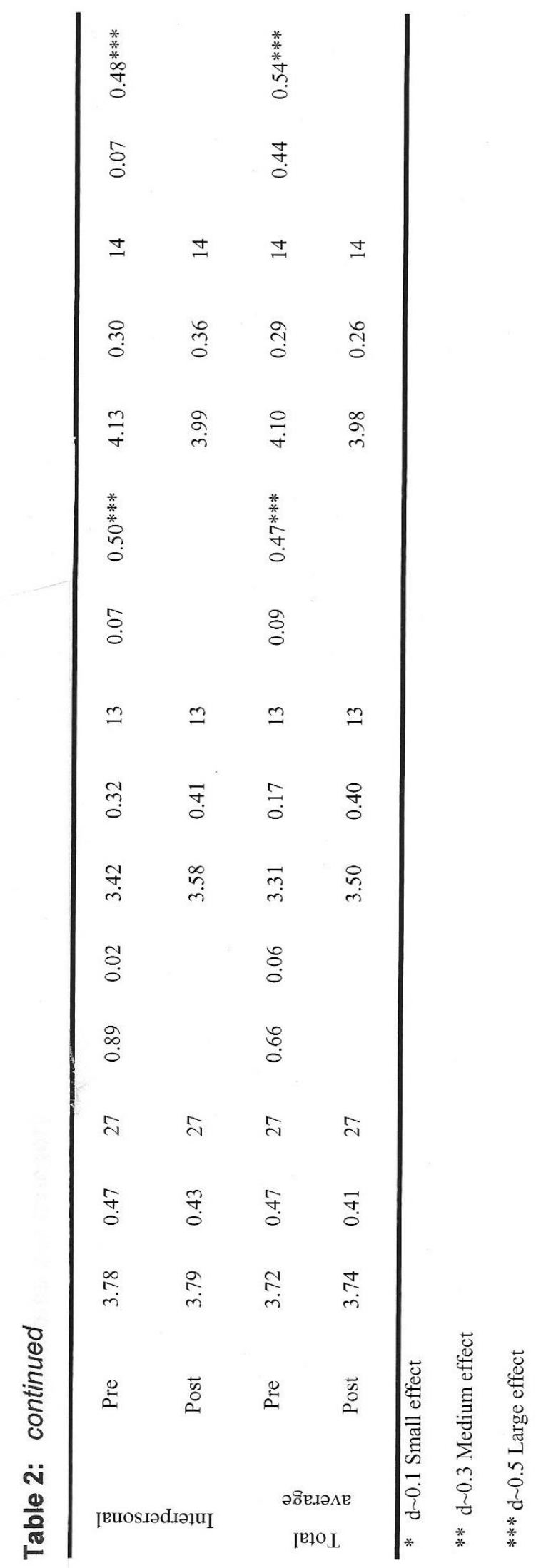


Figures 1, 2 and 3 indicate the SDL scoring range of the total group, the moderate SDL group and the high SDL group for the pre-test and post-test respectively. It is clear that the moderate group gained the most from the intervention.

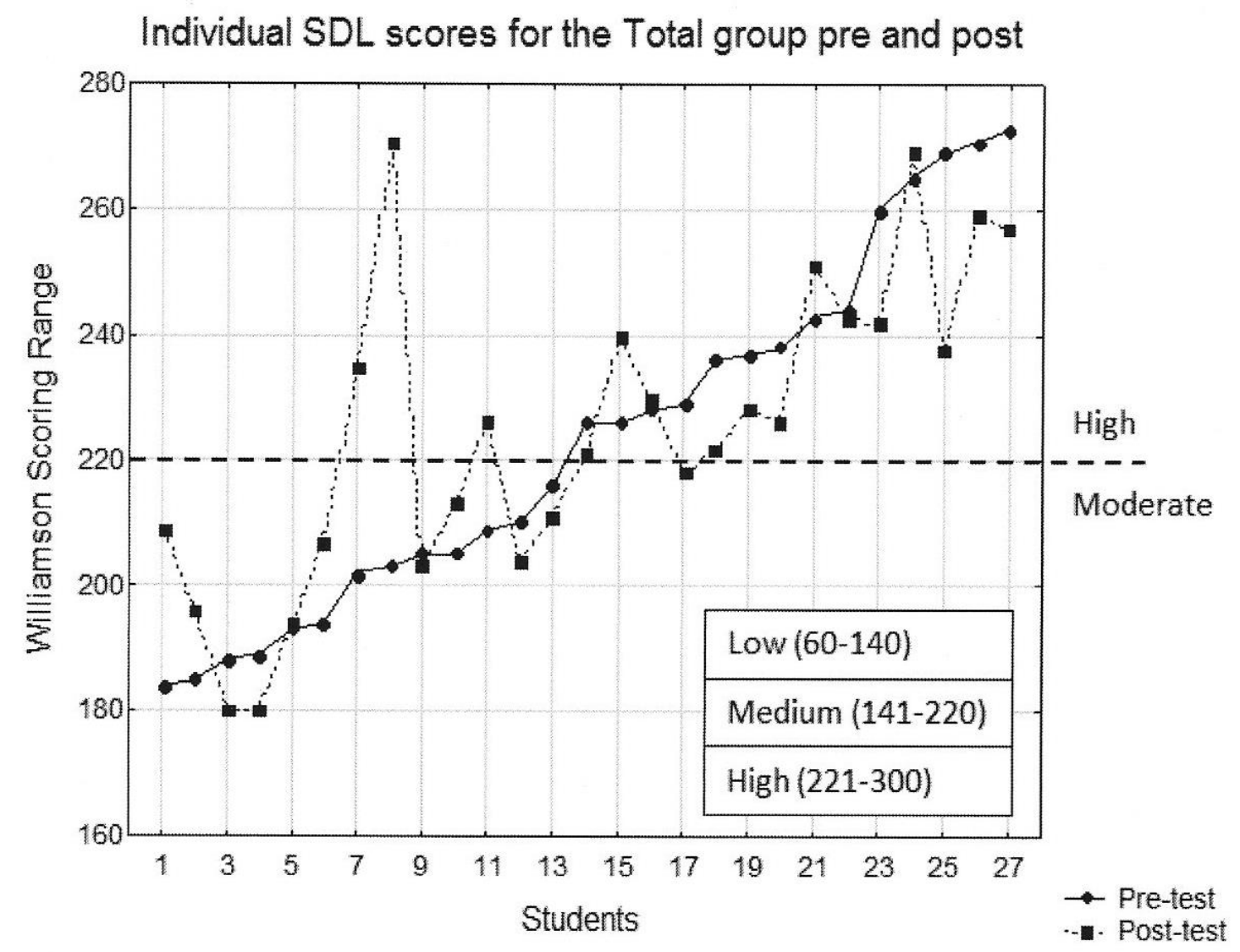

Figure 1: Individual SDL scores for total group. 
Individual SDL scores for the Moderate group pre and post

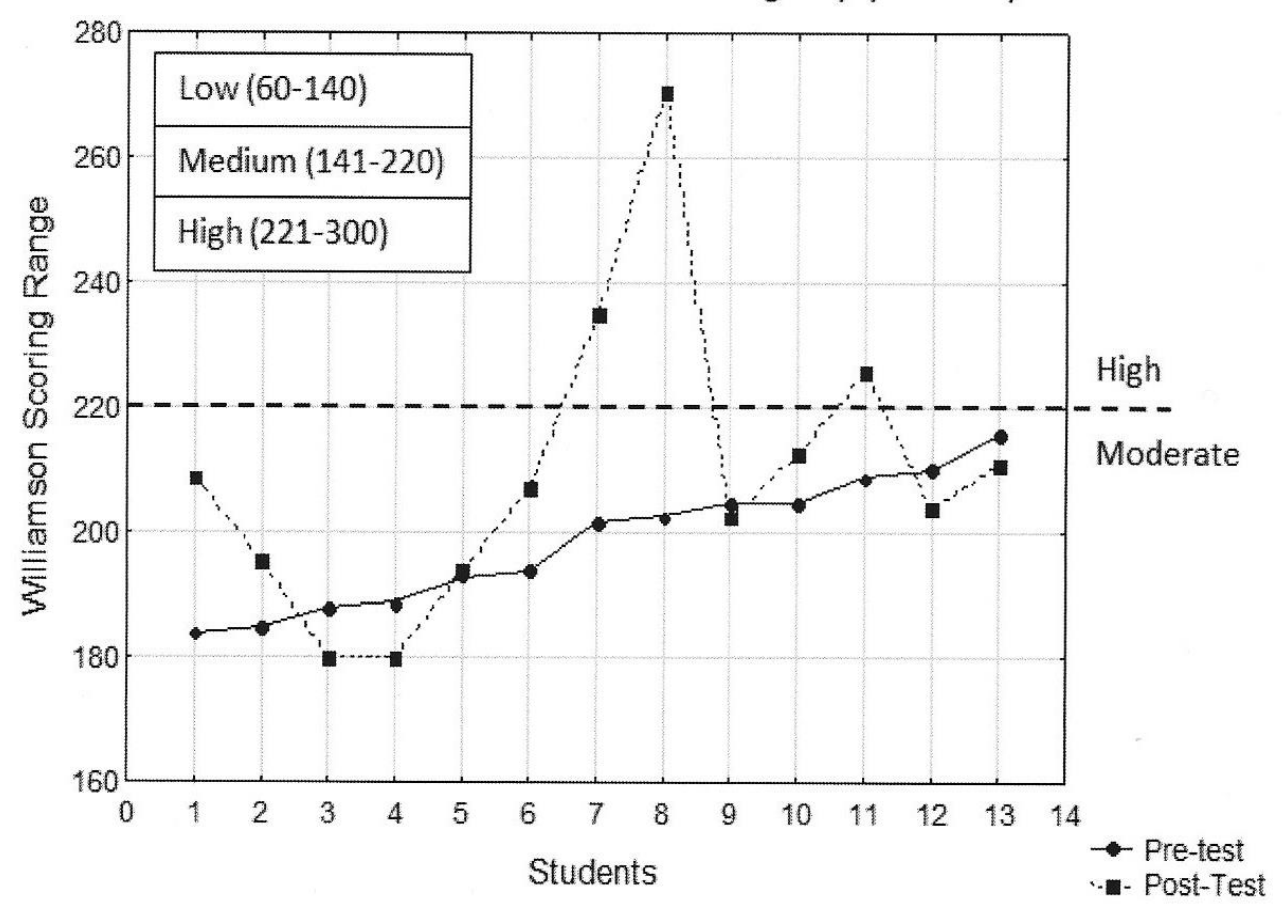

Figure 2: Individual SDL scores for the moderate SDL group.

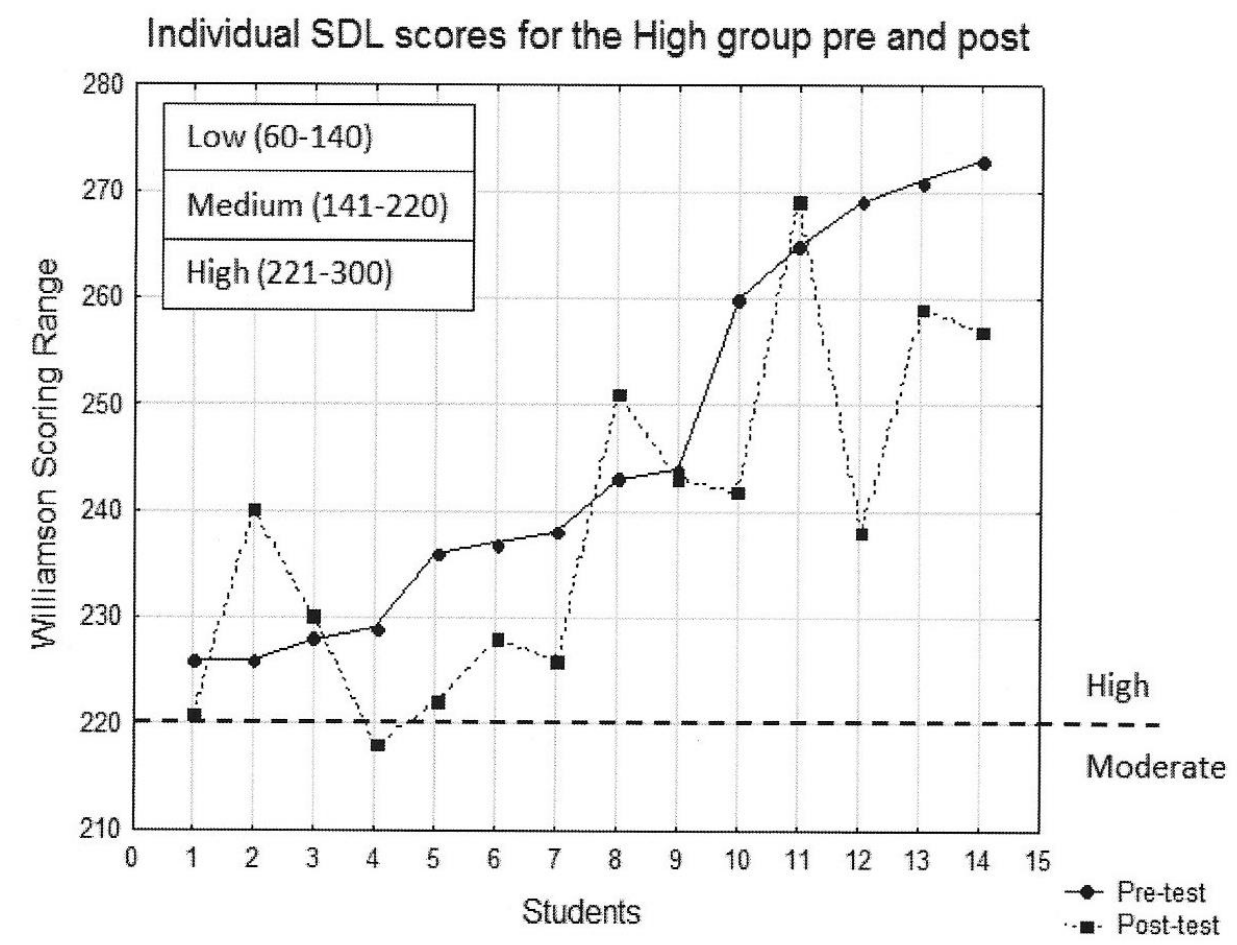

Figure 3: Individual SDL scores for the high SDL group. 
Table 3 summarizes the results of the total groups' perception of cooperative learning before and after the intervention. Although the mean scores indicate an improvement in the students' perceptions towards cooperative learning on all questions after the intervention, this increase has only a small- to medium-effect size.

Table 3: Cooperative learning perception: Pre- and post-intervention total group (Dependent T-test)

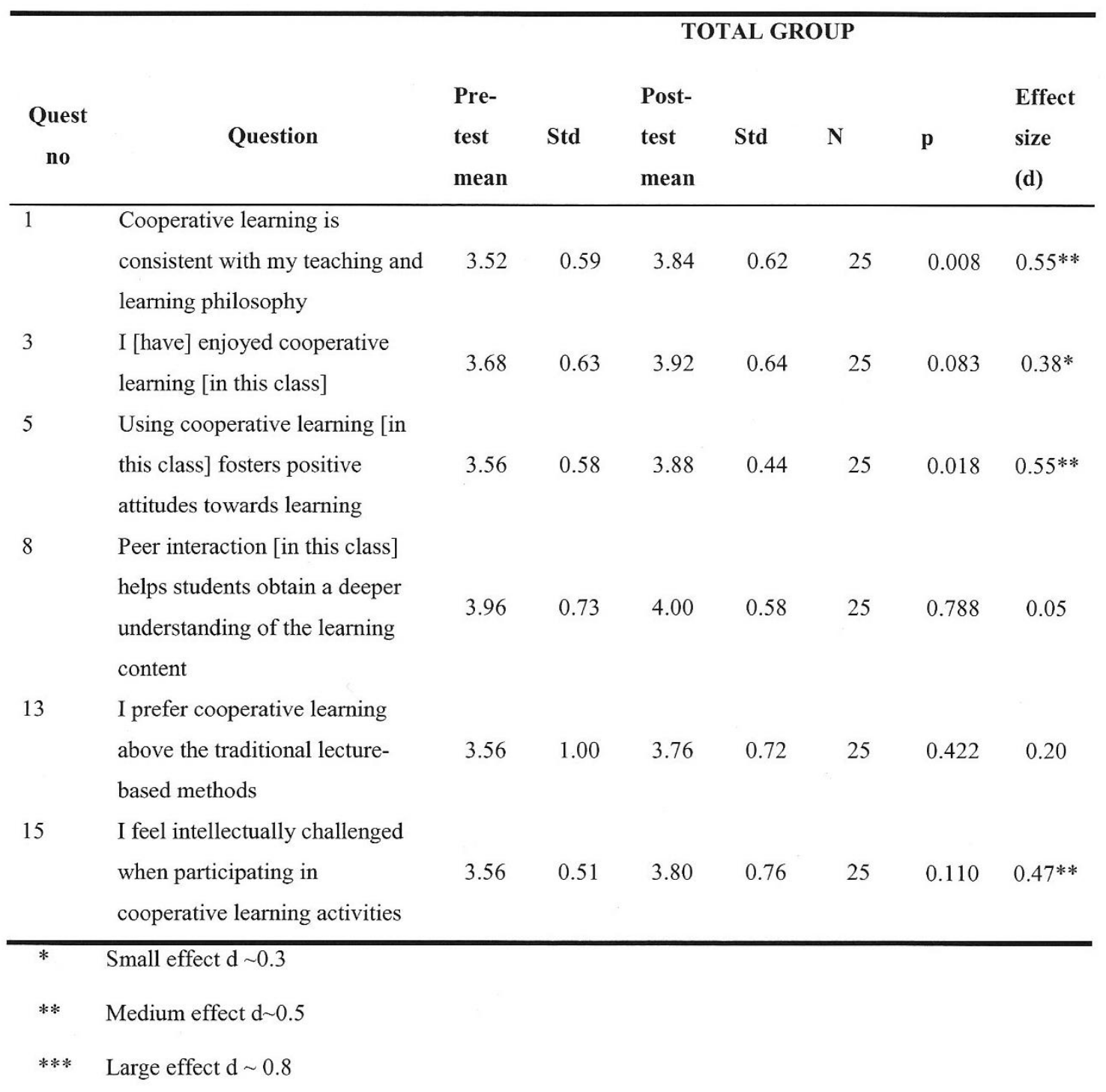


The students seemed to have enjoyed the cooperative learning experience more than they had expected (See Table 3). They experienced deeper understanding of the learning content than they had expected and they now viewed cooperative learning as their preferred strategy.

Table 4 summarizes the results of the moderate and high groups' perceptions of cooperative learning before the intervention and thereafter. The mean scores indicate an improvement in both groups' attitudes towards cooperative learning on all questions after the cooperative learning intervention except for two questions where the high group had a decrease in mean scores. The questions on their preference for cooperative learning and their opinion on peer interaction that resulted in a deeper understanding of the learning context had lower mean scores after the intervention, which were of medium practical significance. They clearly regard the cooperative learning strategy more negatively than the moderate group.

The reasons for the decrease obtained with the high SDL group should be further investigated. It can be speculated that these students' perceptions with the pretest were that they already had a deep understanding of the content. According to Reason, Cox, McIntosh and Terenzini (2010), students must put an effort into engaging in learning activities that results in deeper understanding. Cooperative learning requires students to be responsible for the rest of the group's learning too. The students with high SDL scores might also be the students that are used to working at their own pace without asking others for assistance and are thus not used to taking responsibility for others' learning. Although the students in the high group indicated that they felt intellectually challenged when participating in cooperative learning activities, they seemed to be unable to connect it to a deeper understanding of the learning context. They nevertheless indicated that they enjoyed the cooperative learning experience as their mean scores for enjoyment increased significantly after the intervention. In summary, it can be stated that the high SDL group enjoyed cooperative learning and felt intellectually challenged even though it was not their preferred strategy and they felt that it did not deepen their understanding of the content. 


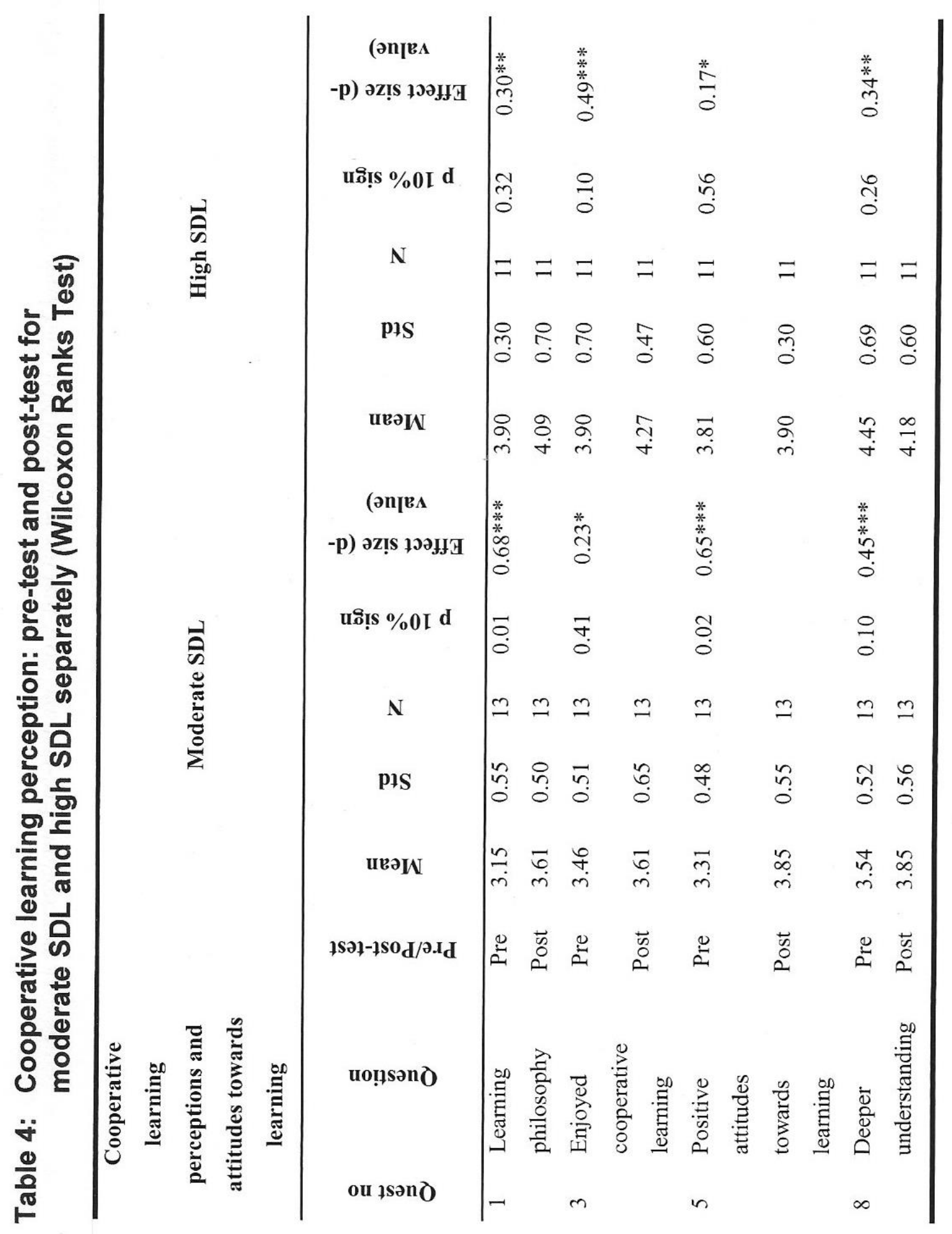




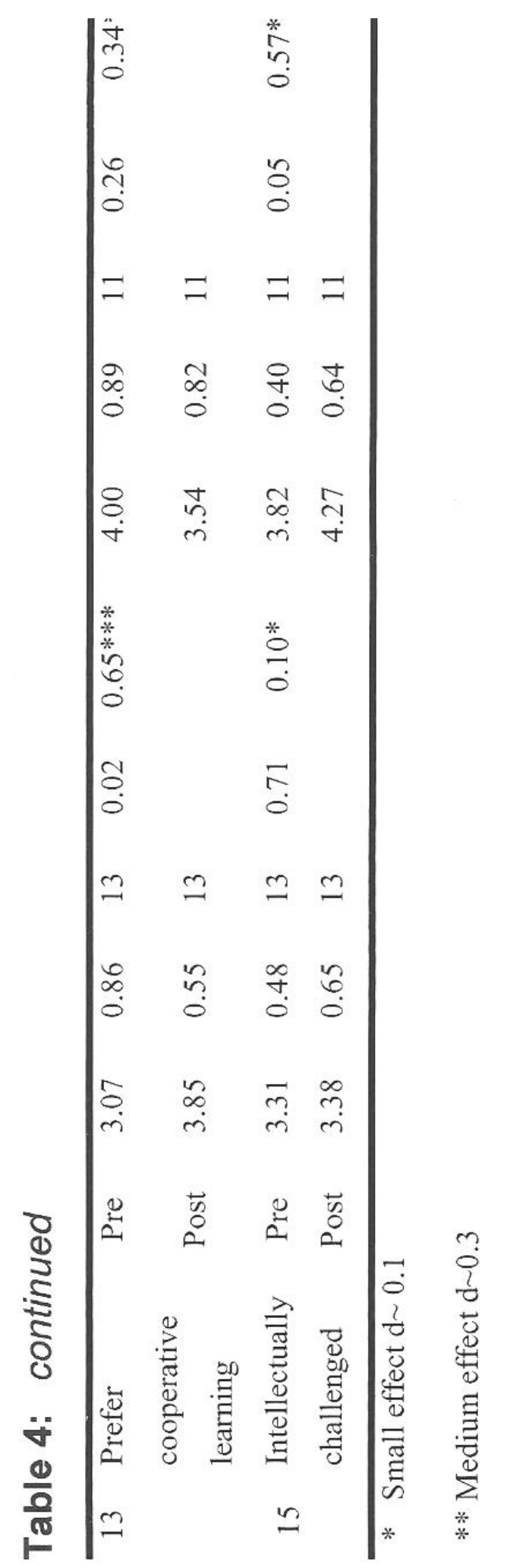


Qualitative data

Themes were identified from the transcriptions of the interviews and classified into cognitive, behavioural and affective components. The following themes emerged and were classified under the cognitive component of attitudes: inquisitiveness, deeper understanding and wider perspective. Themes classified under the behavioural component of attitudes were improved learning methods, social skills, interpersonal interaction and increased personal responsibility. Themes in the affective component of attitudes were increased interest, motivation to learn more, utilisation of resources and enjoyment.

It is clear from the themes that all three components (cognitive, affective and behavioural), essential to changing students' attitudes towards learning were visible in the responses of participants. Although 13 of the 14 respondents indicated that they did not have positive previous experiences of cooperative learning, they all stated that they enjoyed working cooperatively and contrary to the results of the quantitative data, indicated that it was their preferred way of working. Interestingly enough, no negative responses were obtained from the interviews which can shed light on the somewhat negative perceptions obtained from the high SDL group in the quantitative results. Table 5 offers an overview of the main themes, sub-themes and quotes of this qualitative analysis. 
Table 5: Qualitative themes, sub-themes and some quotes

\begin{tabular}{|c|c|c|}
\hline Categories & Themes & Important quote \\
\hline \multirow[t]{3}{*}{ Cognitive } & Inquisitiveness & $\begin{array}{l}\text { - I wanted to know more about it } \\
\text { - I try to find out more about the topic afterwards } \\
\text { - It was very interesting and so I went to read up more after } \\
\text { the class } \\
\text { - I read up more about issues that we discussed in the group } \\
\text { - I then went home and try and get more information on the } \\
\text { Internet }\end{array}$ \\
\hline & $\begin{array}{l}\text { A deeper } \\
\text { understanding of } \\
\text { content }\end{array}$ & $\begin{array}{l}\text { - Everyone understand a different part of the problem and } \\
\text { together it helps us understand everything } \\
\text { - I understand better after the group discussion } \\
\text { - It is easier to understand if someone at your level } \\
\text { explained it }\end{array}$ \\
\hline & $\begin{array}{l}\text { A wider perspective } \\
\text { about field of study }\end{array}$ & $\begin{array}{l}\text { - The discussions gave me a wider perspective on the topic } \\
\text { - I learn to look at the bigger picture }\end{array}$ \\
\hline \multirow[t]{3}{*}{$\begin{array}{l}\text { Behavioral } \\
\text { component }\end{array}$} & $\begin{array}{l}\text { Improved learning } \\
\text { methods }\end{array}$ & $\begin{array}{l}\text { - I learn new and different ways to study } \\
\text { - In the beginning I try to learn on my own, but it is much } \\
\text { better when we study together as a group } \\
\text { - I learn to plan my learning and structure the learning } \\
\text { content }\end{array}$ \\
\hline & $\begin{array}{l}\text { Improved social } \\
\text { skills and } \\
\text { interpersonal } \\
\text { interaction }\end{array}$ & $\begin{array}{l}\text { - I enjoyed the interaction with others } \\
\text { - It helps me to build relationships } \\
\text { - I learn to communicate effectively } \\
\text { - Cooperative learning teach me to listen to other's view } \\
\text { points } \\
\text { - I have benefited from it more than just increased } \\
\text { knowledge ... }\end{array}$ \\
\hline & $\begin{array}{l}\text { Increased personal } \\
\text { responsibility }\end{array}$ & $\begin{array}{l}\text { - I like to learn more and prepare at home to help my group } \\
\text { understand the topic and achieve good scores } \\
\text { - I prepare at home because I do not want to let my group } \\
\text { down } \\
\text { - I prepare better because I know other students depend on } \\
\text { my knowledge }\end{array}$ \\
\hline
\end{tabular}


Table 5: continued

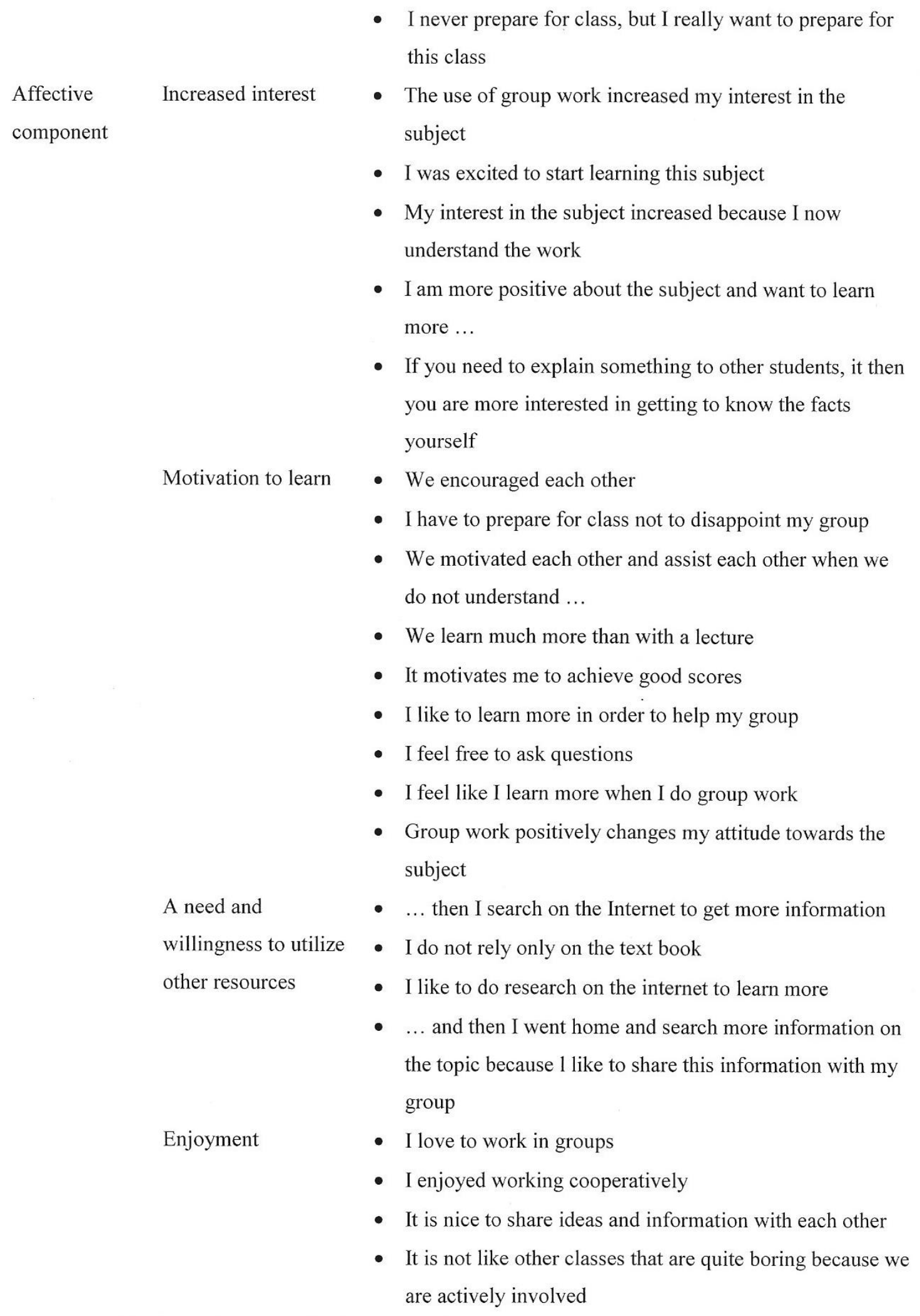




\section{Discussion}

Although not significantly, the overall group showed a slight increase in self-directed readiness after the intervention, and their perception of cooperative learning also increased slightly. This increase, however, cannot necessarily only be linked to the intervention, but can also be the result of students' normal intellectual growth. One of the reasons for using a mixed method approach was to determine whether the qualitative results could possibly shed more light on this issue. The interviews with students, conducted after the intervention, provided a clear indication that students' perception of the cooperative learning intervention was very positive and could also be linked to improved SDL skills. None of the 14 students indicated any negative perceptions about the strategy, although almost all of them indicated that they had been very negative when it was announced that they would have to work cooperatively in this class. From the themes identified and the quotes (see Table 5), it is clear that the intervention changed students' attitudes towards learning in this subject in a positive way. Another important aspect that needs to be mentioned is that the themes inquisitiveness, improved learning methods, improved social skills, increased interest, motivation to learn, a need and willingness to utilise other resources and enjoyment, which relate to students' attitude towards learning also relate to the characteristics of a self-directed learner (see Tables 1 and 5).

When analysing the scores of the moderate and high SDL groups separately, it appeared that the moderate group of students showed a significant increase in their perceived self-directed readiness as well as in their perception of cooperative learning as teaching-learning strategy. The high effect sizes obtained in almost every category of the SDL questionnaire and in each item of the cooperative perception questionnaire provide an indication that those students developed a positive attitude towards their learning. This could be an indication that the cooperative learning intervention contributed to their higher perception of their own self-directed readiness. On the other hand, those students with high perceived SDL readiness at the beginning of the intervention showed a decrease in their perceived SDL readiness even though their SDL-readiness scores were still in the high category. In three of the five categories there were practically significant differences between their pre-test and post-test, indicating that the students perceived themselves as less self-directed after the intervention. It can be argued that the high perceived SDL readiness group did not perceive the cooperative learning intervention as 
positively as the moderate group when only looking at the quantitative results. These students obtained a high score on the cooperative learning perception questionnaire before the intervention, indicating that they preferred cooperative learning to the traditional lecture. However, during the post-test there was a practically significant decrease in their scores, indicating that they did not feel quite as positive about the strategy any more. Surprisingly, however, there was a significant increase in their enjoyment of cooperative learning after the intervention. They also indicated that participating in cooperative learning was intellectually challenging. This may dovetail with the finding by Felder and Brent (2007) that high academic achievers often need to explain or clarify the learning content to the other members of the group, which could be challenging, especially when group members challenge each other's reasoning.

The cooperative learning intervention also did not seem to have a significant influence on the attitudes towards learning of the high-scoring SDL students, as only a small practically significant increase on the scores of this question (Table 4, question 5) was visible. The students scoring high on SDL did not perceive the cooperative learning intervention in the same positive light as the moderate SDL group of students. Where the SDL scores of the moderate group relate positively to their cooperative learning perception scores, it appears as if the decrease in SDL scores for the high group can be coupled with lower cooperative learning perceptions scores.

Nevertheless, students' scores on cooperative learning perceptions, which can influence their attitudes towards learning, were still above 3.00 on the Likert-type scale for all items and for both groups. This may be an indication of the value of the cooperative learning intervention in terms of general attitudes towards learning.

The qualitative interviews underlined the fact that all students had a positive attitude towards their own learning after the cooperative learning intervention. No negative comments were made by students regarding the cooperative learning intervention. It seems that a few students influenced the mean scores of the high group negatively and they were unfortunately not part of the students randomly selected for the interviews. Remarks made by some of the students point to an increase in terms of SDL readiness. During the interviews, it was also confirmed that even students with high SDL scores did not experience any negativity towards cooperative learning, but that they had a willingness to learn more. They were more motivated to prepare for classes, 
to use resources other than their textbooks and they indicated an overall willingness to take responsibility for their own learning, all of which are indicative of a higher SDL.

\section{Conclusion}

According to students in the first-year Computer Applications Technology class, the cooperative learning intervention fostered a positive attitude towards learning. The quantitative and qualitative results confirm that students had an even more positive attitude towards learning after the six-month intervention, which may be attributed to the cooperative learning strategy applied in this class. From a theoretical perspective, the relationship between cooperative learning, attitudes towards learning and SDL was indicated. Through the qualitative interviews, it was evident that the positive attitudes towards learning also contributed to students' SDL skills as the sub-themes inquisitiveness, improved learning methods, improved social skills, increased interest, motivation to learn, a need and willingness to utilise other resources and enjoyment can all be linked to characteristics of a self-directed learner. Although the results of the quantitative research for the total group show no significant improvement of SDL scores after the cooperative learning intervention, there was a significant improvement in SDL scores for students initially scoring themselves in the moderate SDL category. These students also improved significantly on their attitudes towards learning. It can thus be concluded that students' attitudes towards learning related to their self-directedness for those students initially in the moderate SDL category. More research should be done to determine why students' SDL scores in the high SDL category decreased after the intervention, even though no supporting evidence could be found qualitatively. The fact that their scores on attitudes towards learning only slightly increased after the intervention indicates that they did not perceive the cooperative learning intervention in the same positive light as the students in the moderate SDL category. The same close relationship between their attitudes and SDL scores could not be found for students initially scoring themselves high on SDL. 
Acknowledgement

This work is based on a research project supported by the National Research Foundation (NRF) of South Africa (Grant Number 90387). The grant holder acknowledges that opinions, findings and conclusions or recommendations expressed in any publication generated by the NRF-supported research are those of the author(s), and that the NRF accepts no liability whatsoever in this regard.

\section{References}

Acikgoz Un, K. 2007. Etkili Ogrenme ve Ogretim. Bilis.

Ahonen, E., Pyhältö, K., Pietarinen, J. and Soini, T. 2015. Becoming a teacher - student teachers' learning patterns in teacher education. Journal of Education and Training Studies, 3(5): pp.89-101.

Aiken, L. 1996. Rating scales and checklists: evaluating behavior, personality and attitudes. New York, NY: Wiley.

Blumberg, P. 2000. Evaluating the evidence that problem-based learners are self-directed learners: a review of the literature. In Evensen, D. and Hmelo, C.E. (Eds). Problem-based learning: a research perspective on learning interactions. Mahwah, NJ: Lawrence Erlbaum, pp.199-226.

Brown, H.D. 1980. Principles of language learning and teaching. Englewood Cliffs, NJ: Prentice-Hall.

Collins, A., Joseph, D. and Bielaczyc, K. 2004. Design research: theoretical and methodological issues. Journal of the Learning Sciences, 13(1): pp.15-42.

Creswell, J.W. 2008. Education research: Planning, conducting, and evaluating quantitative and qualitative research 3rd ed.. Upper Saddle River, NJ: Pearson.

Creswell, J.W. 2009. Research design: qualitative, quantitative, and mixed methods approaches (3rd edn.). London: Sage. 
Davidson, C.N. 2012. Now you see it: how technology and brain science will transform schools and business for the 21st century. New York, NY: Penguin Books.

Farooq, M.S. and Shah, S.Z.U. 2008. Students' attitude towards mathematics. Pakistan Economic and Social Review, 46(1): pp.75-83.

Farzaneh, N. and Nejadansari, D. 2014. Students' attitudes towards using cooperative learning for teaching reading comprehension. Theory and Practice in Language Studies, 4(2): pp.287-292.

Felder, R.M. and Brent, R. 2007. Cooperative learning. In Mabrouk, P.A. (Ed.), Active learning: models from the analytical sciences. ACS Symposium Series 970. Washington, DC: American Chemical Society, pp.34-53.

Field, A. 2005. Discovering statistics using SPSS. London: Sage.

Francom, G.M. 2010. Teach me how to learn: principles for fostering students' self-directed learning skills. International Journal of Self-Directed Learning, 7(1): pp.29-44.

Gardner, R.C. 1985. Social psychology and second language learning: the role of attitudes and motivation. Baltimore, MD: Edward Arnold.

Grow, G.O. 1991. Teaching learners to be self-directed. Adult Education Quarterly, 41(3): pp.125-149.

Guglielmino, L.M. 1978. Development of the self-directed learning readiness scale. Unpublished doctoral dissertation. University of Georgia, Athens.

Guglielmino, L.M. 2013. The case for promoting self-directed learning in formal educational institutions. SA-eDUC Journal, 10(2).

http://www.nwu.ac.za/content/2013-volume-10-number-2. [Date of access 25 March 2016].

Hmelo-Silver, C.E. 2004. Problem-based learning: what and how do students learn? Educational Psychology Review, 16(3): pp.235-266. 
Idros, S.N.S., Mohamed, A.R., Esa, N., Samsudin, M.A. and Daud, K.A.M., 2010. Enhancing self-directed learning through e-SOLMS for Malaysian learners. Procedia - Social and Behavioral Sciences, 2(2): pp.698-706.

Johnson, D.W. and Johnson, F.P. 1999. Making cooperative learning work. Theory into Practice, 38(2): pp.67-73.

Johnson, D.W. and Johnson, F.P. 2013. Joining together: group theory and group skill (11th edn). Upper Saddle River, NJ: Pearson.

Kelly, A.E., Baek, J.Y., Lesh, R.A. and Bannan-Ritland, B. 2008. Enabling innovations in education and systematizing their impact. In Kelly, A.E., Lesh, R.A. and Baek, J.Y. (Eds), Handbook of design research methods in education. New York, NY: Routledge, pp.3-18.

Knowles, M.S. 1975. Self-directed learning: a guide for learners and teachers. New York, NY: Association Press.

Lohman, M.C. and Finkelstein, M. 2000. Designing groups in problem-based learning to promote problem-solving skill and self-directedness. Instructional Science, 28: pp.291-307.

Long, H.B. and Associates. 2000. Practice and theory in self-directed learning. Schaumburg: Motorola.

Ma, X. and Kishor, N. 1997. Assessing the relationships between attitude toward mathematics and achievement in mathematics: a meta-analysis. Journal for Research in Mathematics Education, 28(1): pp.26-47.

Mackenzie, N., and Knipe, S. 2006. Research dilemmas: Paradigms, methods and methodology. Educational Research, 16. Retrieved from http://www.iier.org.au/iier16/mackenzie.html

Malan, S.B., Ndlovu, M. and Engelbrecht, P. 2014. Introducing problem-based learning (PBL) into a foundation programme to develop self-directed learning skills. South African Journal of Education, 34(10): pp.1-16. 
Mentz, E., Van der Walt, J.L. and Goosen, L. 2008. The effect of incorporating cooperative learning principles in pair programming for student teachers. Computer Science Education, 18(4): pp.247-260.

Mertens, D.M. 2005. Research methods in education and psychology: integrating diversity with quantitative and qualitative approaches (2nd edn) Thousand Oaks, CA: Sage.

Parsons, S.A. and Ward, A.E. 2011. The case for authentic tasks in content literacy. The Reading Teacher, 64(6): pp.462-465.

Raidal, S.L. and Volet, S.E. 2009. Preclinical students 19 predispositions towards social forms of instruction and self-directed learning: a challenge for the development of autonomous and collaborative learners. Higher Education, 57(5): pp.577-596.

Reason, R.D., Cox, B.E., McIntosh, K. and Terenzini, P.T. 2010. Deep learning as an individual, conditional, and contextual influence on first-year student outcomes. Presented at the Annual Forum of the Association for Institution Research, Chicago, IL. May 31, 2010.

Richardson, V. 1996. The role of attitudes and beliefs in learning to teach. In Sikula, J., Buttery,T.J. and E. Guyton (Eds), Handbook of research on teacher education (2nd edn). New York, NY: Macmillan, pp.102-119.

Sen, H.S. 2013. The attitudes of university students towards learning. International Journal of Academic Research, 5(4): pp.338-342.

Shimazoe, J. and Aldrich, H. 2010. Group work can be gratifying: understanding and overcoming resistance to cooperative learning. College Teaching, 58: pp.52-57.

Slavin, R.E. 1991. Are cooperative learning and untracking harmful to the gifted? Educational Leadership, 48(6): pp.68-71.

Tan, I.G.C., Lee, C.K.E. and Sharan, S. 2007. Group investigation effects on achievement, motivation, and perceptions of students in Singapore. Institute of Education, 100(3): pp.142-154. 
Warburton, N. and Volet, S. 2012. Enhancing self-directed learning through a content quiz group learning assignment. Active Learning in Higher Education, 14(9): pp.9-22.

Wenden, A.L. 1991. Learner strategies for learner autonomy. London: Prentice Hall.

Williamson, S.N. 2007. Development of a self-rating scale of self-directed learning. Nurse Researcher, 14(2): pp.66-83.

Yenilmez, K. 2007. Attitudes of Turkish high school students toward mathematics. International Journal of Educational Reform, 16(4):

pp.318-335.

Elsa Mentz

Sukie van Zyl

Faculty of Education Sciences

North-West University

elsa.mentz@nwu.ac.za

sukie.vanzyl@,nwu.ac.za 
